\title{
Rouse's Thought on Scientific Knowledge and Power
}

\author{
Kai Xu \\ Wuhan University of Science and Technology \\ Wuhan, China
}

\begin{abstract}
Traditionally, knowledge exists in accurate presentation and scientific knowledge is the model of knowledge. "A wide gap" exists between the world and its presentation. Scientists are to "bridge this gap" through improving the presentation. Rouse addresses traditional opinions on knowledge and power and their relationship fail to understand the contemporary scientific practice and its relationship with politics and society, and it is a "serious misguidance". Therefore, it is necessary to redefine knowledge and power and review the interaction between them. According to systematic understanding of works written by Rouse, we find the progressive significance of Rouse's idea can be highlighted through comparing the scientific knowledge and power of Rouse with the traditional ideas on knowledge and power.
\end{abstract}

\section{Keywords—power; knowledge; tradition; science}

\section{INTRODUCTION: TRADITIONAL OPINIONS ON KNOWLEDGE AND POWER}

Traditionally, knowledge exists in accurate presentation and scientific knowledge is the model of knowledge. "A wide gap" exists between the world and its presentation. Scientists are to "bridge this gap" through improving the presentation. The power in traditional view refers to the compulsory force politically, the dominant power in job scope or defense force endowed by law. Power is "possessed and executed by specific actors". Some power such as duty power is occupied by a few people and not universal. Power can only act on "people's presentation" instead of changing it, let alone acting on "the presented world". Power is "oppressive" and "delegated" but not "creative" and "productive". The application of knowledge can gain or resist the power. Although power can be used to impede or distort "the acquisition of knowledge", it cannot alter the truth. The relationship between power and knowledge is external and "both of them are not influenced by each other".

Rouse addresses traditional opinions on knowledge and power and their relationship fail to understand the contemporary scientific practice and its relationship with politics and society, and it is a "serious misguidance" and "fails to conform to the ways of power operation" as well as "misunderstands scientific practice and its political influence". Therefore, it is necessary to redefine knowledge and power and review the interaction between them. Specifically speaking, it mainly includes:

\section{KNOWLEDGE Is PRACTICE (UNDERSTAND SCIENCE FROM PRACTICE)}

Because the presentationism of knowledge encounters insurmountable gap in solving the problem of "fidelity of theory", scientific research changes from theory dominance to actual operation, with Kuhn and new empiricists as main representatives. They observe the key of scientific knowledge is not the accurate presentation of things but successful operation of things, which is the main characteristic of contemporary science. Therefore, "knowledge does not connect with statement, skill or pattern separately or momentarily. The epistemology position of knowledge depends on the relationship between it and other practices and skills, especially the recovery, transformation and extension of these relationships".

In future research and applications, things are regarded as sources of activities. In this sense, application may cause misunderstanding because in the most extensive sense, we don't acquire knowledge first and then apply it. Knowledge must be treated as something explained through many ways in application. Undoubtedly, Rouse's ideas that understand science through practice and knowledge is practice form on this basis. Rouse holds the opinion that knowledge is treated as "practice area" instead of "theoretical presentation", with the most outstanding representative of Kuhn. In the book of Structure of Science Revolutions, he brings a great favorable turn for philosophy of science. Most importantly, he emphasizes understanding science through practice, which is ignored and misunderstood by many philosophers of science.

In explanation of Kuhn's work, the focus of dispute is between the knowledge-based view of presentationism with theory dominance and the practical outlook of specific operation with practice dominance. Rouse calls them Kuhn and Kuhn respectively. In Kuhn's opinion, "paradigm is not the theoretical position to gain recognition" but the operating skill necessary in special experience and situation. "The acceptance of paradigm is more acquisition and application of a skill than the understanding of theoretical system." It is a comprehensive skill, including determination of research target and object, formulation and control of research methods and procedures, selection and application of instruments and equipment, construction, separation and intervention of research object, strategy to grasp concrete situation and opportunities to intervene special experiment situation. The most important skill is to know how to deal with new situation. Obviously, in Kuhn's opinion, in understanding and acceptance of paradigm, scientific 
research through paradigm, facing abnormal crisis even scientific revolution and the replacement of old paradigm with new paradigm, the most necessary is the skill to intervene specific situation and solve problems through actual operation instead of the theoretical system that must be understood.

New empiricists and Kuhn reach consensus on the relationship between science and practice. They think "science is not to improve the accuracy of presentation of things but to improve our ability in dealing with affairs". After seriously researching opinions of Kuhn and new empiricists, Rouse proposes the idea that scientific knowledge is practice. It means scientific knowledge is not the accurate presentation of objective things but the skill for successful operation and control of things. Traditionally, knowledge achievements are separated from its application. However, Rouse addresses they are inseparable, namely, knowledge achievements are the ability for successful operation and control of things. Rouse redefine the scientific knowledge here.

To sum up, science is not presentation and way to observe the world but one or multiple ways in operation and intervention of the world. Scientists are practitioners instead of observers.

\section{THE RELATIONSHIP BETWEEN KNOWLEDGE AND POWER TRANSFORMS FROM BEING MUTUAL EXTERNAL TO BEING MUTUAL INTERNAL}

Although under the significance of scientific knowledge newly defined, no internal relationship exists between knowledge and power, so we must redefine power. Although the word means power, ability, energy and intelligence, power and influence as well as political power, traditionally speaking, the power refers to the latter.

Feminists propose "knowledge is power" including the two meanings. Foucault expands the meaning of power that contains the above two meanings. After analyzing and researching forms and characteristics of modern power, Foucault proposes the macro-power in political and legal sense in traditional view has been expanded as micro-power in social meaning, which reflects the characteristics of modern power. Rouse is influenced by Foucault's idea in power in the research of scientific knowledge and power. When inheriting Foucault's idea in power, Rouse airs his opinions and redefines Foucault's power theory. Rouse concludes power is the force for successful operation of things, making the concept of power more meaningful in the epistemological perspective. The exertion object of power expands from human body and faith to material object. Meanwhile, the source of power is also expanded. Human is the source of power, and science becomes the greater source of power. The function of power expands from "dominance of people on people" to "successful operation of things". In this way, knowledge and power unify. Rouse gives wonderful discussion "in traditional view, knowledge achievements are separated from its application. In this way, power is regarded as the application of knowledge".
Because new empiricists transform knowledge from accurate presentation to the control of successful operation of things, in their opinion, the above differentiation cannot establish. Power is not longer exclusive from knowledge or opposite to knowledge but becomes the symbol of knowledge. (2) Knowledge integrates with power. Knowledge is power, power is knowledge.

\section{POWER FOCUSING ON LABORATORY}

In Rouse's opinion, "Foucault regards panopticon as implicit model of concrete society, and laboratory provides more accurate realization model for the world of calculation".

Nowadays, the object of scientific research is not "natural" but "artificial". Scientists do not observe the world outdoors but research and produce phenomenon in laboratory Modern scientific knowledge is not traditional general laws but the skills for successful operation of things, namely the ability to operate, control, intervene and transform things in laboratory. The knowledge power model in laboratory has been expanded to modern society even modern world.

Except for producing "artificial objects" in laboratory, modern science produces knowledge in laboratory. Therefore, the ways and methods of scientific development change fundamentally. Scientific knowledge is "local" knowledge produced in laboratory instead of the "general law" "effective anytime and anywhere". Therefore, the transmission mode is "from local knowledge to another local knowledge" instead of "being from universal knowledge to local knowledge". Knowledge development also happens in laboratory. Knowledge is produced and operated in laboratory. Repeating in this way, new knowledge produces continuously and expands to other places. Knowledge is diffused and applied.

We can find that knowledge is circulated and proved internally, so Rouse draws a conclusion that "there are innumerable truths but no essential truth; similarly, there is scientific knowledge but no essential scientific knowledge". He further observes "the knowledge and power model in laboratory has been expanded to the whole modern society even modern world". Traditionally, knowledge is called as the universal truth that is effective any time any where, so it can be applied to any local area. Rouse holds the opposite opinion that "the development of the contemporary latest scientific philosophy has revealed the 'image' of local knowledge. The relationship between knowledge and world is no longer the application of general principles to specific situation. Instead, it means local knowledge produced in local context expands to another context".

Knowledge is produced in specific situation, so it is local knowledge instead of general rule. Different specific situations lead to different knowledge application. Although some basic truths with knowledge characteristics are provided, we cannot establish the worldwide unified view, or neither realizing repeated transmission of proposition in time and space nor guaranteeing it keeps unchanged". Therefore, the relationship between knowledge and world is that local 
knowledge turns to another local knowledge, instead of the transformation of universal knowledge to local knowledge.

But does it mean theory and law are thoroughly ineffective in the relationship between knowledge and the world? The answer of Quine enlightens us. “...We don't cut off the past. No evidence and reliable standard can distinguish the scientific understanding from the ambiguous understanding of children and outsiders. Science is not a substitute but a judgment of common sense." Rouse concludes "It is stupid to thoroughly deny the vital function of theory and law in the development and transfer of scientific knowledge. I think we need to reconsider it. Theory and law exist in specific examples. The abstract forms understood through examples are meaningful in specific application. The usage is "transferred" again to repeat or change in different situations".

\section{CONCLUSION}

Rouse's theory on scientific knowledge and power is not saying that the traditional power "has disappeared or no longer influences science", but to say we cannot ignore or deny the "micro-power". The typical characteristics of modern power form manifested by it have "penetrated in the most common activities of scientific research". The outlook on power is not to replace but to supplement the traditional outlook on power.

\section{REFERENCES}

[1] Wu Tong: Scientific Practice in the Philosophical Perspective of Scientific Practice-Review on Scientific Practice View of Rouse [J], Philosophical Researches, 2006(6): 85-91

[2] Rouse J. Knowledge and Power: Toward a Political Philosophy of Science[M]. NY: Cornell University Press, 1987.

[3] Rouse J. Engaging Science: How to Understand Its Practices Philosophically[M]. NY: Cornell University Press, 1996.

[4] Rouse J. How Scientific Practices Matter: Reclaiming Philosophical Naturalism[M]. Chicago: University of Chicago Press,2002.

[5] Rouse, Knowledge and Power-Toward a Political Philosophy of Science[M], Beijing: Peking University Press, 2004. 